\title{
microRNA-98 mediated microvascular hyperpermeability during burn shock phase via inhibiting $\mathrm{FIH}-1$
}

\author{
Delin Hü, Youxin Yu, Chunhua Wang, Denghui Li, Yuncheng Tai and Linsen Fang
}

\begin{abstract}
Background: microRNA is a small non-coding RNA molecule and functions in RNA silencing and post-transcriptional regulation of gene expression. This study was designed to evaluate the role of miR-98 in the development of microvascular permeability and its molecular pathogenesis.

Methods: Forty-eight healthy adult Wistar rats were divided into the control group $(n=8)$ and burn group $(n=40)$ that inflicted with 30\% total body surface area third-degree burn. Groups were processed at 2, 4, 8, 12, and $24 \mathrm{~h}$ post-burn. Plasma for vascular endothelial cell culture was collected from control and $12 \mathrm{~h}$ post-burn rats. Organic microvascular permeability and serum miR-98 level were measured. In vitro, rat aorta endothelial cells were stimulated with burn serum. Level of miR-98 and protein of hypoxia-inducible factor-1 (HIF-1), factor inhibiting HIF-1a (FIH-1), and tight junction-associated proteins were determined.

Results: Organic microvascular permeability began to rise at $2 \mathrm{~h}$ post-burn and maintained the same character throughout the experiment except in lung tissue that was still rising at $12 \mathrm{~h}$; the serum level of miR-98 was elevated $(P<0.05)$. In vitro, burn serum stimulation increased rat aorta endothelial monolayer cell permeability as well as upregulated miR-98 expression $(P<0.05)$. As shown in the result of transfection experiment, miR-98 negatively regulated $\mathrm{FlH}-1$ and tight junction-associated protein expression $(P<0.05)$.

Conclusions: The findings of the present study suggest severe microvascular permeability due to burns; and the underlying mechanism bases on the promotion of miR-98 level to the extent that it activated HIF-1 gene expression, resulting in junction-associated protein deficiency.
\end{abstract}

Keywords: Burn, FIH-1, miR-98, HIF-1a, Microvascular permeability

\section{Background}

The skin serves as a vital protective barrier against exterior harmful factors, and the disruption of its integrity can lead to patients' significant disability or even death. Clinically, nearly 20 million annual hospital admissions are attributable to burns. Among these, the third-degree burn is the most threatening for injured patients and is characteristic of damage in all layers of skin, as well as muscles and possibly organs. Importantly, it is generally accepted that the burn injury-induced ischemic internal organs may contribute to the development of sepsis and multiple organ dysfunction [1-3], mainly including

\footnotetext{
* Correspondence: Hu_del@163.com

Department of Burns, The First Affiliated Hospital of Anhui Medical University, No. 218 Jixi Road, Hefei, Anhui Province 230022, People's Republic of China
}

increased microvascular permeability [4]. Given this, better insight into the molecular mechanisms underlying pathogenic conditions related to microvascular hyperpermeability is required for developing effective therapeutic strategies for burn injury.

The integrity of microvascular permeability is mainly maintained by tight endothelial cell-cell junctions, which are composed of a large complex of proteins including the integral proteins such as claudins, occludin, and the peripheral membrane proteins such as zonula occludens (ZO-1 and ZO-2) [5,6]. Among these, ZO-1 is one of the most often investigated proteins and it is mainly responsible for connecting the integral membrane protein to the actin cytoskeleton and different types of signaling proteins [6]. Increasing evidences suggest that hypoxia- 
inducible factor-1 (HIF-1) that mediated adaptive cellular responses to hypoxia upregulates the expression and plays critical roles in paracellular barrier functions, including epithelial barrier [7-10]. HIF-1 protein consists of subunits HIF- $1 \alpha$ and HIF- $1 \beta$ among which HIF- $1 \alpha$ protein level is the dominant factor for HIF-1 transcriptional activity [11]. HIF-1-targeting genes are correlated with loss of ZO-1 and increased paracellular permeability [12-15]. Thus, efforts to attenuate the accumulation of HIF- $1 \alpha$ may benefit burn patients who are at high risk for vascular organic permeability. In cells, the level and activity of HIF-1 are controlled by asparaginyl factor-inhibiting HIF-1 (FIH-1) hydroxylases. FIH-1 was originally found to be a negative regulator of HIF-1 and was later shown to be an asparaginyl hydroxylase, capable of hydroxylating N803 in the C-terminal activation domain (CAD) of human HIF-1 [16-18].

Although proteins have been established as basic regulatory factors in accommodation to alterations in environment, our knowledge of the contribution of regulatory micro-RNA molecules is gradually aggregating. As is known that microRNA is a small non-coding RNA molecule and functions in RNA silencing and post-transcriptional regulation of gene expression. Its important role in mediating the pathological process of ischemia has been identified. Especially, miR-98, a subset of HIF-1-inducible miRNAs, was found expressed to the greatest extent during ischemia [19]. In this study, we attempt to investigate whether miR-98 is involved in burn injury-induced vascular permeability and to investigate the molecular mechanism underlying burn-induced microvascular hyperpermeability in both rat model of burn injury and microvascular endothelial monolayer model of burn serum triggering.

\section{Methods}

\section{Animal models}

The protocol was approved by the Committee on the Ethics of Animal Experiments of the Anhui Medical University of Science and Technology. Male Wistar rats were obtained from the Institute of Laboratory Animal Resources at Anhui Medical University (8 to 10 weeks, weighing $271 \pm 10 \mathrm{~g}$ ) and were housed in mesh cages in a room maintained at $25^{\circ} \mathrm{C}$, illuminated with $12: 12$-h light-dark cycles and provided with standard rodent chow and water ad libitum. For experiment, 48 mice were randomly divided into two groups: control group $(n=8)$ and burn operation group $(n=40)$. Full-thickness burn injury occupying $30 \%$ of total body surface area was produced as described by Ikezu et al [20]. After the rat was deeply anesthetized with pentobarbital sodium $(25 \mathrm{mg} / \mathrm{kg}$ ), the hair on its back was removed with electric hair clippers and the skin was depilated with $8 \%$ sodium sulfide. Rats were subjected to scald injury by smearing with $3 \%$ napalm for burning $18 \mathrm{~s}$. The operation resulted in 30\% total body surface area (TBSA) III degree burns. Preliminary histological investigation established the presence of a deep partial-thickness burn wound using the described protocol (data not shown). Burn-mice were intraperitoneally injected with Lactated Ringer's Solution (40 ml/kg) for anti-shock. Following burn injury, animals received a subcutaneous injection of $0.5 \mathrm{ml}$ normal saline with $0.1 \mathrm{mg} / \mathrm{kg}$ of buprenorphine (Sigma, St. Louis, MO, USA) for pain control. Mice in the control group were treated in proportion except burn injury operation. Burned rats did not display discomfort or pain, and all rats consumed food and water within $45 \mathrm{~min}$ of the burn procedure.

Plasma was harvested from either control rats or burned-rats $2,4,8,12$, and 24 h post-injury ( 8 rats per time phase). The rats were deeply anesthetized with methoxyflurane, and aorta abdominalis was used to collect blood into plasma separator tubes containing lithium heparin (Microtainer, Becton, Dickinson and Company, Franklin Lakes, NJ, USA). The tubes were then centrifuged at $200 \mathrm{~g}$ for $10 \mathrm{~min}$. The plasma was aliquoted and stored at $-80^{\circ} \mathrm{C}$ for miR-98 detection. Additionally, plasma from control and 12-h post-burn rats was collected and was performed with $56^{\circ} \mathrm{C}$ water-bath for $30 \mathrm{~min}$ in order to inactivate serum complements and then filtrated with a 0.22 -um filter membrane. The plasma was finally aliquoted and stored at $-80^{\circ} \mathrm{C}$ for vascular endothelial cell culture.

\section{Organ microvascular permeability assay}

For the permeability assay, vascular protein leakage was measured using the Evans blue (EB) technique. After deep anesthetization, EB $(20 \mathrm{mg} / \mathrm{kg}$ weight; Sigma, St. Louis, MO, USA) was injected intravenously through the femoral vein. Thirty minutes after dye injection, the animals were euthanatized, and a midline thoracotomy was performed. Then the superior and inferior vena cavae were ligated, the aorta was transected, and $20 \mathrm{ml}$ of NS was injected into the right ventricle at a pressure of $20 \mathrm{~cm} \mathrm{H}_{2} \mathrm{O}$ to wash out the internal organs' intravascular content. A sample of lung, liver, ileum, and kidney tissue was weighed, immersed in $\mathrm{N}, \mathrm{N}$-dimethylformamide (Sigma), and homogenized. The homogenate was incubated at room temperature for $48 \mathrm{~h}$. Eluted EB was measured at $620 \mathrm{~nm}$ using an automatic microplate reader (SpectraMax M5; Molecular Devices, Sunnyvale, CA, USA), and the amount was expressed as micrograms per 100 mg dry tissue.

\section{Endothelial cell culture and treatment}

Rat aortic endothelial cells (RAECs) were purchased from Genlantis (San Diego, CA, USA). RAECs maintained at $37^{\circ} \mathrm{C}$ in $5 \% \mathrm{CO}_{2}$ in Dulbecco's Modified Eagle's 
Medium (DMEM; Hyclone Laboratories, Logan, UT, USA) containing $10 \%$ fetal bovine serum. Cells at passages 3 to 10 were used in this study. For subsequent study, confluent cultures were stimulated with burn serum (10\% of DMEM) for $24 \mathrm{~h}$ accompanied by normal serum incubation as control.

\section{Transfections with miRNA mimics and inhibitors}

Rat aortic endothelial cells $\left(2 \times 10^{5}\right)$ were transfected with 10 to $50 \mathrm{nM}$ anti-miR-98 miRNA inhibitors (Ambion, Austin, TX, USA) or scrambled control (Negative Control 1; Ambion) by using Lipofectamine 2000 from Invitrogen (Carlsbad, CA, USA) according to the manufacturer's protocol.

\section{Quantitative real-time PCR (qRT-PCR)}

For miR-98 expression analysis, total RNAs were extracted with Trizol reagent (Invitrogen, Carlsbad, CA, USA) according to the protocols of the manufacturer followed by DNA-free DNase treatment (Ambion, Austin, TX, USA). The total RNAs were inversely transcribed into cDNA using the Revert Aid $^{\mathrm{Tm}}$ First Strand cDNA Synthesis Kit (Thermo Scientific, Grand Island, NY, USA) according to the manufacturer protocols. For amplification, the PCR was performed in a total reaction volume of $20 \mathrm{ml}$ with $5 \mu$ of cDNA template, $500 \mathrm{nM}$ forward primer, $500 \mathrm{nM}$ reverse primer, and $10 \mu \mathrm{l}$ of $\mathrm{SsoFast}^{\mathrm{TM}}$ EvaGreen $^{\oplus}$ Supermix (Bio-Rad, Mississauga, ON, USA) and was completed in the ABI PRISM 7000 Fluorescent Quantitative PCR System (Applied Biosystems, Foster City, CA, USA). U6 was used as an internal control.

\section{Transendothelial cell electric resistance}

All resistance measurements were conducted by an epithelial voltohmmeter (World Precision Instruments, Sarasota, FL, USA) with STX2 chopstick electrodes (World Precision Instruments). A 12-well tissue culture plate (Sigma, St. Louis, MO, USA) was inserted with 12-mm transwell inserts that have been coated with a solution of human fibronectin (Sigma, St. Louis MO, USA) dissolved in PBS at a concentration of $50 \mu \mathrm{g} / \mathrm{ml}$ for $6 \mathrm{~h}$ at $25^{\circ} \mathrm{C}$. After pre-treated with $10 \mu \mathrm{l}$ burn serum or control serum in DMEM complete medium for $24 \mathrm{~h}$, RAECs with the incubating medium were plated in the multiwall inserts and then cultured for an additional 5 to 7 days until the transendothelial electric resistance (TEER) was $\geq 20 \mathrm{ohm} \times \mathrm{cm}^{2}$. In other experiments, using the same culture conditions to establish TEER $\geq 20$ $\mathrm{ohm} \times \mathrm{cm}^{2}$, RAECs were transfected with miR-98 inhibitor and/or control siRNA or sequence specific siRNA directed against FIH-1 in 10\% fetal bovine serum (FBS) for $24 \mathrm{~h}$.

\section{Western blot assay}

The lung tissues were homogenized and analyzed for HIF-1 $\alpha$, FIH-1, and junction-associated proteins by Western blotting. Protein concentrations were determined using the bicinchoninic acid method. An equal amount of protein was loaded onto $10 \%$ sodium polyacrylamide hydrophilic gel for electrophoretic separation. After electrophoresis, proteins were electroblotted onto polyvinylidene fluoride (PVDF) membranes (Millipore, Billerica, MA, USA) and blocked in 10\% nonfat milk. Following, the proteins were blotted with primary antibodies against HIF-1 $\alpha$, FIH-1, Occludin, Claudin-1, and ZO-1 (Abcam, Cambridge, United Kingdom) and $\beta$-actin (Tianjin Sungene Biotech Co., Ltd., Tianjin, China) at $4^{\circ} \mathrm{C}$ overnight. The next day, the blots were recognized by horseradish peroxidase-tagged secondary antibody (Santa Cruz, CA, USA) incubation. Finally, the protein expressions were represented using an enhanced chemiluminescence method, and the images were visualized using ChampGel (Sage Creation Science Co, Beijing, China).

\section{Permeability coefficient of albumin}

The permeability of the endothelial cell monolayer was performed with a two-compartment system that was separated by a filter membrane. Briefly, both compartments contained that same basal medium modified Tyrode's solution (composition in mM: $150 \mathrm{NaCl}, 2.7 \mathrm{KCl}, 1.2$ $\mathrm{KH} 2 \mathrm{PO} 4,1.2 \mathrm{MgSO} 4,1.0 \mathrm{CaCl}$, and $30.0 \mathrm{~N}$-2-hydroxyethylpiperazine- $\mathrm{N}^{\prime}$-2-ethanesulfonic acid; $\mathrm{pH} 7.4,37^{\circ} \mathrm{C}$ ) supplemented with $2 \%$ ( $\mathrm{vol} / \mathrm{vol}) \mathrm{NCS}$ and were with no hydrostatic pressure gradient. The monolayer in a luminal' compartment possessed a volume of $2.5 \mathrm{ml}$ and that in an 'abluminal' compartment possessed a volume of $6.5 \mathrm{ml}$. The medium in the abluminal compartment was constantly stirred. The luminal compartment was added with trypan blue-labeled albumin $(60 \mu \mathrm{M})$. The appearance of the labeled albumin in the abluminal compartment was continuously monitored by pumping the liquid through a spectrophotometer (Specord 10; Carl Zeiss, Thornwood, NY, USA). The concentration of labeled albumin in the luminal compartment was determined every 10 min of incubation. It did not change significantly in the time frame of the experiments.

The albumin across the monolayer with the surface were represented as permeability coefficient $(\mathrm{Pa}): \mathrm{Pa}=([A] /$ $t) \times(l / A) \times(v /[L])$. [A] is the luminal compartment albumin concentration, $t$ is the time interval showed in seconds, $A$ is the area of glomerular capillary membrane showed in $\mathrm{cm}^{2}, v$ is the fluid volume of abluminal compartment showed in $\mathrm{ml},[L]$ is albumin concentration of abluminal compartment. The result was presented as percentage change of $\mathrm{Pa}$ : Equation $\mathrm{Pa} \%=($ test $\mathrm{Pa} /$ control $\mathrm{Pa}) \times 100$. 


\section{miRNA target reporter luciferase assay}

MiR-98 predication of potential targets FIH-1 3'UTR was performed with miRanda software. Fragments of 3'UTR of FIH-1 gene harboring the predicted miR-98binding sites were cloned into the firefly luciferase reporter plasmid pMIR-Report (Ambion) according to the manufacturer's protocol. After 24 to $48 \mathrm{~h}$ transfection, cells were harvested and lysed, and luciferase reporter activities were measured using Dual-Glo ${ }^{\circ}$ Luciferase Assay System (Promega, Madison, WI, USA). Firefly luciferase activity was normalized to Renilla luciferase activity and total protein, determined using the bicinchoninic acid (BCA) protein assay kit. Values for cells without miRNA mimic transfection were set equal to 1 .

\section{Luciferase activity}

Rat aortic endothelial cells $(2 \times 105)$ were stably transfected with HIF-1 $\alpha$ luciferase reporter (RC0017, Panomics,
Fremont, CA, USA) and seeded in complete media (DMEM with 10\% FBS) in 24-well plates. Luciferase activity was measured on hour 24 with HIF-1 alpha Transcription Factor Assay (ab133104; Abcam, Cambridge, MA, USA) according to protocol. In brief, cells were lysed by each well being added with cell lysis solution. Then, lysates mixed with ATP mix served as the substrate for the chemiluminescent oxidation-reduction reaction which leads to light emission and oxy-luciferin generation. The reaction liquid was measured with a luminometer at a light of $560 \mathrm{~nm}$.

\section{Statistical analysis}

All of the experiments were performed with samples in triplicate or greater, and the data are presented as the mean \pm standard deviation $(\mathrm{SD})$ of observations. The experimental groups were compared by one-way or two-way analysis of variance followed by a post hoc Tukey's test.

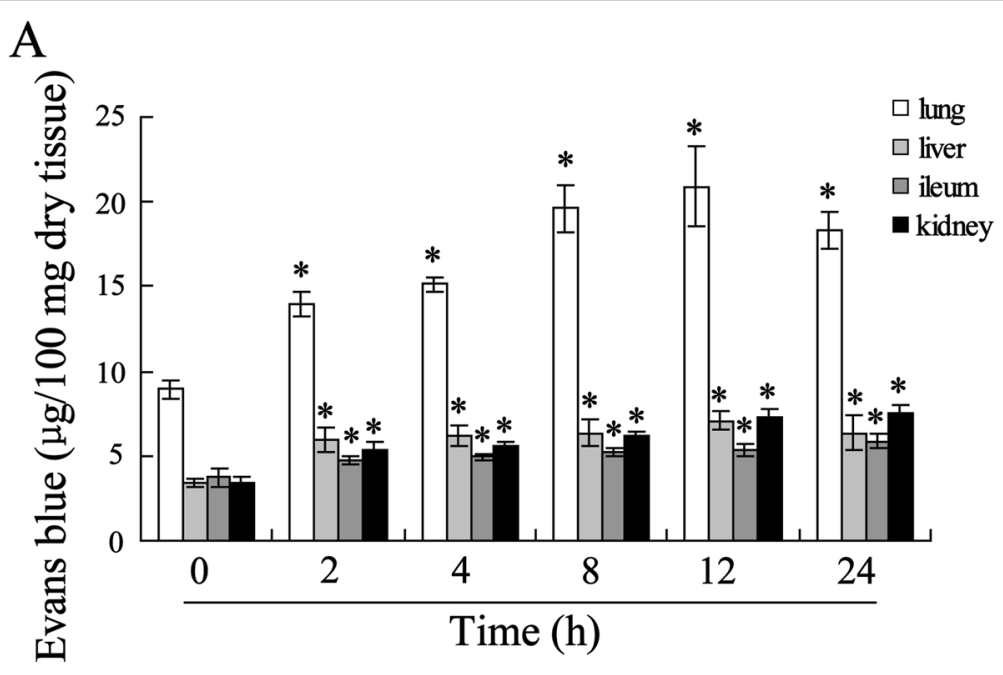

B

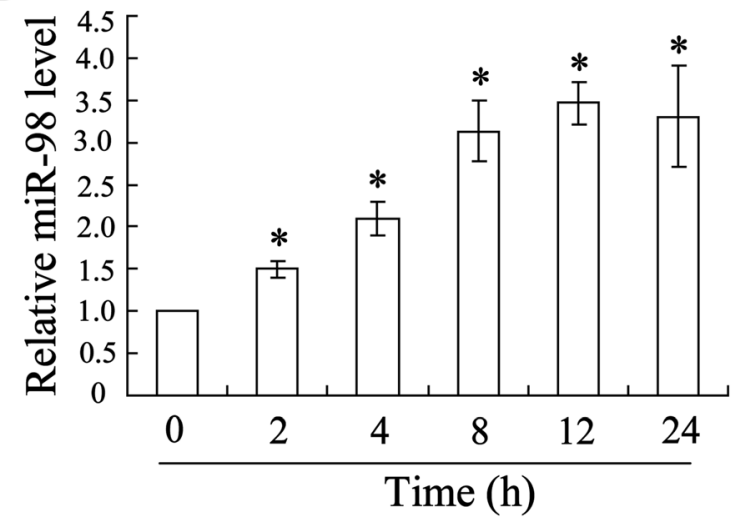

Figure 1 Burns induced increase of vascular permeability. Mice burn model was established, and then on different time points after surgery, mice were euthanatized for the following detection. (A) Vascular permeability was evaluated using Evans blue contents in tissues. (B) Levels of miR-98 in serum was determined using quantitative real-time PCR. The data were represented with mean \pm SD. ${ }^{*} P<0.05$ compared with corresponding control. 
Differences were considered statistically significant if the $P$ value was less than 0.05 .

\section{Results}

\section{Changes in organic microvascular permeability in} burn-injured rat

We assessed changes in organic vascular permeability in mice model of burn using Evans blue assay. The Evans blue contents were determined regularly and began to increase significantly as early as hour 2 , peaked at hour 12, and sustained a high level in lung tissues. While in tissues of the liver, ileum, and kidney, compared with no burn, Evans blue contents were also increased at hour 2, but maintained the same level in the following $22 \mathrm{~h}$ (Figure 1A). Level of serum miR-98 was evaluated, and the data showed an increase in a time-dependent manner and peaked on hour 12 (Figure 1B).

\section{Burn serum stimulation increased permeability of rat aorta endothelial cell monolayers}

To investigate the possible mechanism underlying burninduced microvascular permeability, in vitro burn injury models of rat aorta endothelial monolayer cells stimulated with burn serum were utilized in the experiment. Incubation cells with burn serum led to miR-98 upregulation (Figure 2A) that corresponds to the observation in Figure 1B. It has been well accepted that an insufficient amount of tissue perfusion after burn results in ischemia anoxic damage of cells [21]. Thus we detected protein expression of hypoxia-inducible factor-1 (HIF-1) and factor inhibiting HIF-1 $\alpha$ (FIH-1). As shown in Figure 2B, burn serum stimulation increased $\mathrm{FIH}-1$ expression while decreased HIF- $1 \alpha$ expression. Following, profiles of tight junction-associated proteins were evaluated and the results showed there is no change in Occludin and
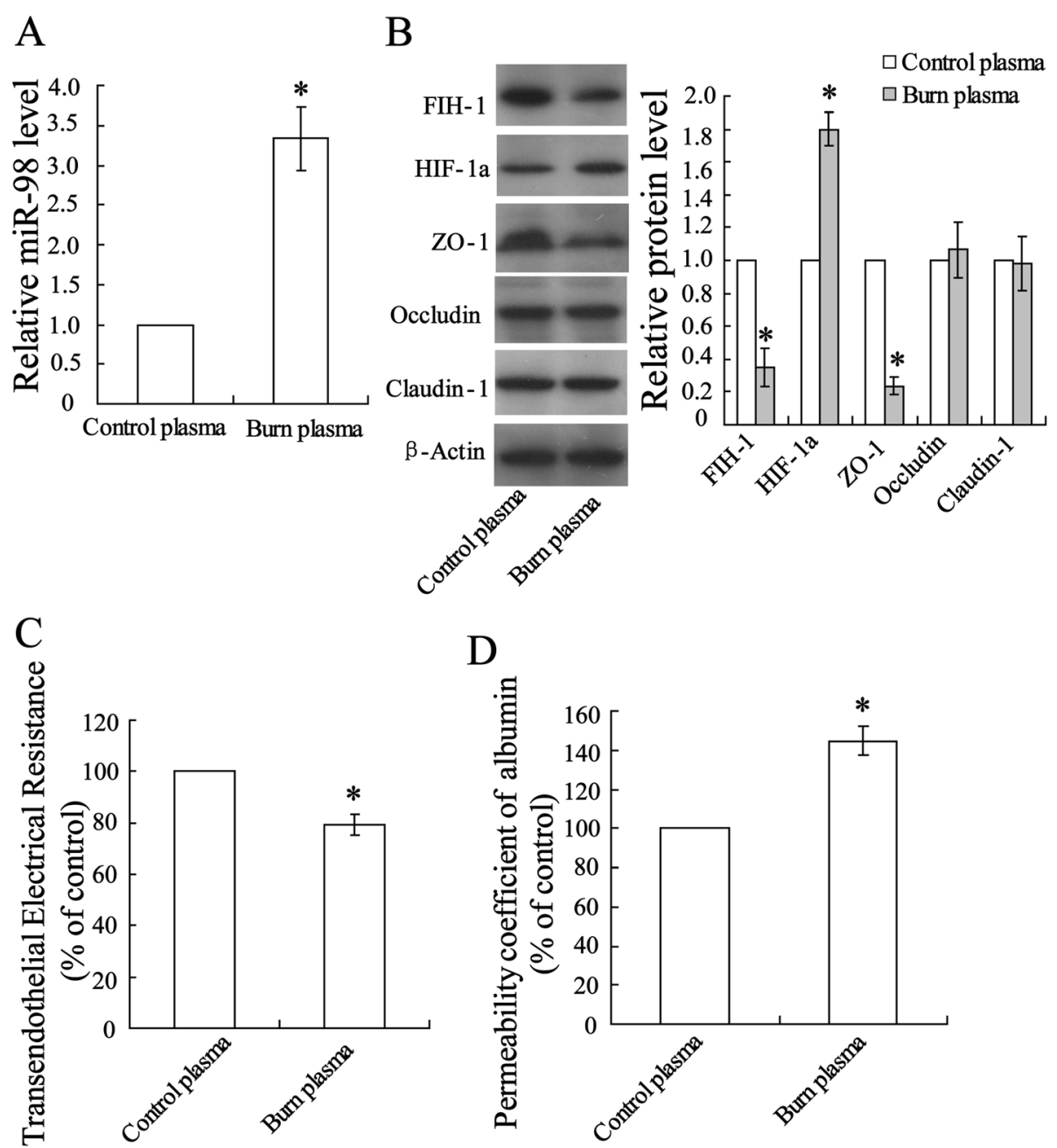

Figure 2 Burn serum stimulation increased permeability of rat aorta endothelial cell monolayers. Rat aorta endothelial cells were incubated with burn serum for $12 \mathrm{~h}$. (A) Level of miR-98 expression was determined using quantitative real-time PCR. (B) Profiles of tight junction-associated proteins expression were evaluated using Western blot. (C) Transendothelial electrical resistance and (D) permeability coefficient of albumin were performed with monolayer endothelial cells. The data were represented with mean \pm SD. ${ }^{*} P<0.05$ compared with control plasma. 
Claudin-1 expression except ZO-1. The permeability of endothelial cell monolayers was evaluated using transendothelial electrical resistance assay (Figure 2C) and permeability coefficient of albumin (Figure 2D). Burn serum reduced transendothelial electrical resistance and increased albumin permeability indicating increased permeability of the endothelial cell.

\section{miR-98 negatively regulated $\mathrm{FIH}-1$ expression in rat aorta} endothelial cell

To investigate the regulating role of miR-98 in FHI-1 expression in rat aorta endothelial cell, miR-98 was knocked down by cells transfected with miR-98 inhibitor. Forty-eight hours after transfection, FIH 3'UTR activity was elevated (Figure 3A) and FIH-1 protein level was upregulated, while HIF-1 protein was downregulated (Figure 3B). HIF- $1 \alpha$ transcription factor activity was attenuated (Figure 3C). When miR-98 was overexpressed by miR-98 mimic transfection, FIH 3'UTR activity was decreased (Figure 3D) and FIH-1 protein level was downregulated, while HIF-1 protein was upregulated (Figure 3E). Consequently, HIF-1 $\alpha$ transcription factor activity was enhanced (Figure 3F).

\section{Silenced miR-98 abrogated burn serum-increased permeability in rat aorta endothelial cells}

Rat aorta endothelial cells were pretreated with miR-98 inhibitor and then stimulated with burn serum. Protein levels are represented by Western blot in Figure 4A and the result showed a reversing effect of silenced miR-98 on burn serum-reduced FIH-1 expression and burn serum-induced FIH-1 expression as well as burn serumreduced ZO-1 expression. Additionally, the permeability of endothelial cell monolayers was evaluated using transendothelial electrical resistance assay (Figure 4B) and permeability coefficient of albumin (Figure 4C). The results also showed the abrogating effect of silenced miR-98 on burn serum-reduced transendothelial electrical resistance and increased albumin permeability suggesting a protective effect of silenced miR-98 on endothelial cell monolayer permeability.

\section{Knock down FIH-1 abrogated silenced miR-98-reduced permeability in rat aorta endothelial cells}

In view of our previous observations that miR-98 inhibitor treatment can increase FIH-1 expression and reversed burn-induced permeability, we next investigated the
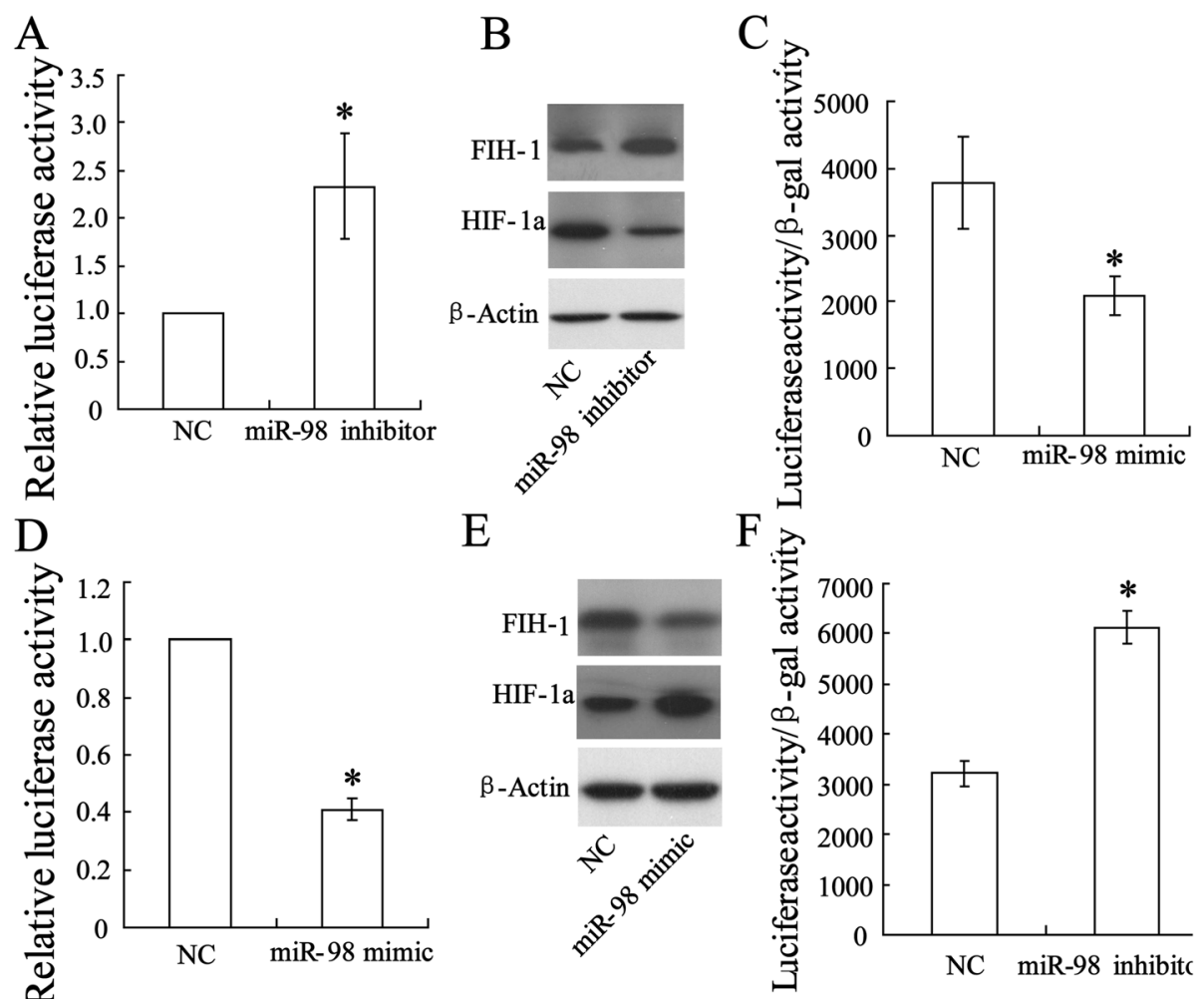

Figure 3 Regulated role of miR-98 in FlH-1 expression in rat aorta endothelial cell. Knock down of miR-98 by miR-inhibitor (A) increased FlH 3'UTR activity, (B) suppressed HIF-1 expression, and (C) inactivated HIF-1 transcription. Overexpression of miR-98 by miR-98 mimic transfection (D) inhibited FIH 3'UTR activity, (E) promoted HIF-1 expression, and (F) increased HIF-1 transcription activity. The data were represented with mean \pm SD. ${ }^{*} P<0.05$ compared with negative control. 


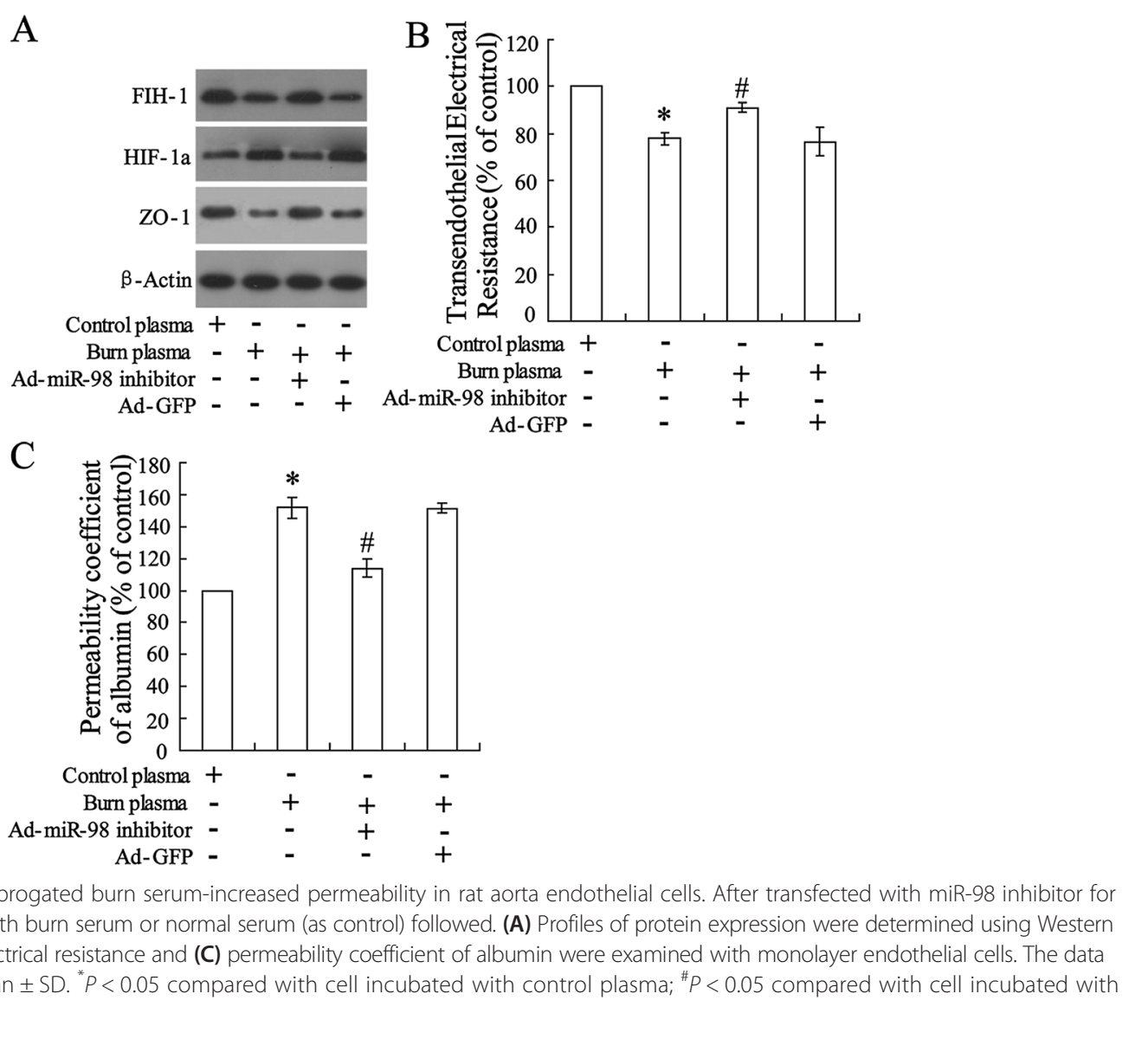

outcome of siRNA-mediated gene depletion of HIF-1 on the silenced miR-98-reduced monolayer endothelial cell permeability. As shown in Figure 5A, co-transfected miR98 inhibitor with siRNA-FIH-1 reversed silenced miR-98reduced ZO-1 expression. The permeability of endothelial cell monolayers was evaluated. The results showed that the abrogating effect of silenced miR-98 on burn serumreduced transendothelial electrical resistance was inhibited by siRNA-FIH-1 treatment (Figure 5B). And abrogating effect of silenced miR-98 on burn serum-increased albumin permeability was also suppressed (Figure 5C).

\section{Discussion}

Increased organic microvascular hyperpermeability induced by severe burns is a fatal threat for patient survival. In this study, we attempted to explored the innate underlying mechanism of burn-triggered microvascular hyperpermeability change during burn injury and explore potential therapy target (Figure 6). From the result, we found out that miR-98 are the key regulators in burn-induced internal organ endothelial dysfunction via inhibiting FIH-1 expression. Our data support that major burn injury induces miR-98 accumulation, which suppressed FIH-1 gene transcription, leading to loss of tight junction-associated $\mathrm{ZO}-1$ protein and the subsequent increase in lung microvascular barrier permeability. Thus, our results provided the possible therapeutic target that elevated FIH-1 by inhibiting miR-98 results in accumulation of HIF-1-mediated adaptive cellular responses to burn-induced ischemia and upregulation of the expression of junction-associated genes that protects against burninduced internal organ epithelial barrier dysfunction.

Burn injury is a common trauma, and the internal organs are some of the most vulnerable distant organs that are affected by extensive burns [22]. Recent studies have shown that pathophysiology of burn-induced internal organ damage is derived from endothelial cell dysfunction [23]. This symptom was also presented in our in vivo experiments in which burn stimuli significantly increase microvascular permeability of the liver, ileum, kidney, and lung. It is well known that, as a semipermeable barrier, endothelial cell in vascular actively participates in blood-tissue exchange of plasma fluid, proteins, and cells and is essential for maintaining 

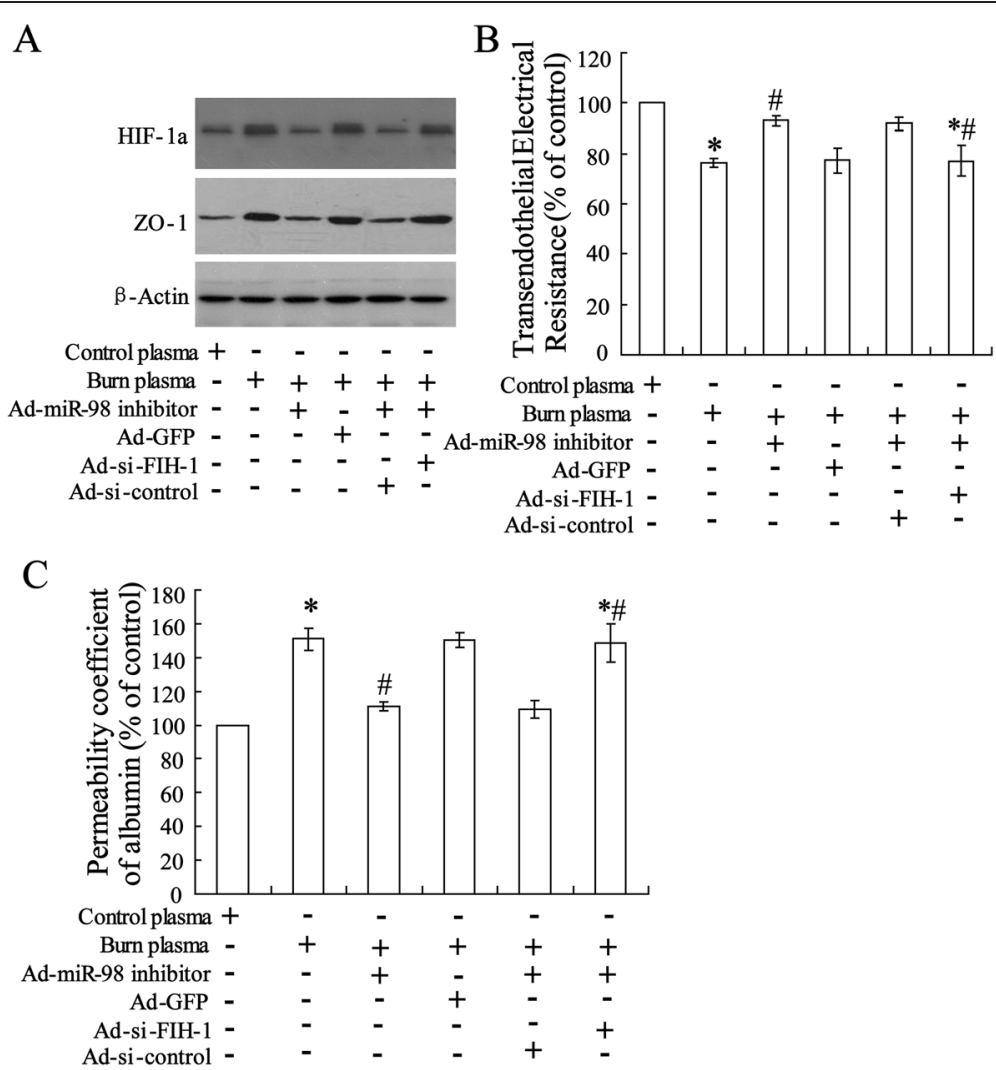

Figure 5 Co-silenced $\mathrm{FIH}-1$ abrogated silenced miR-98-reduced permeability in rat aorta endothelial cells. Cells were pretreated with siRNA-FIH-1 followed by transfection with miR-98 inhibitor. After 48 h, the cells were incubated with burn serum or control serum. (A) Profiles of protein were determined using Western blot. (B) Transendothelial electrical resistance and (C) permeability coefficient of albumin were performed with monolayer endothelial cells. The data were represented as mean \pm SD. ${ }^{*} P<0.05$ compared with control plasma; ${ }^{\#} P<0.05$ compared with burn serum; ${ }^{*} P<0.05$ compared with burn serum + miR-98 inhibitor.

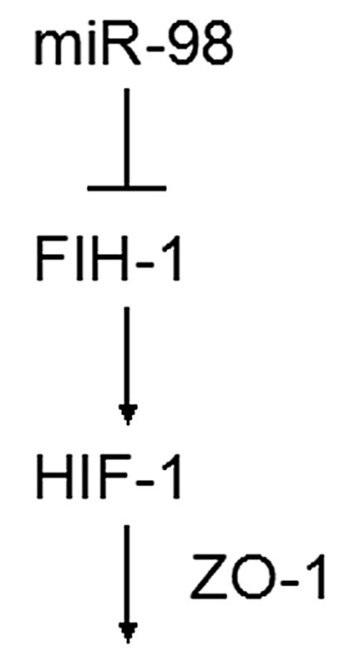

microvascular permeability

Figure 6 Signaling mechanism by which miR-98 mediated burn-induced increase of microvascular permeability. circulatory homeostasis [24] that plays an important role in burn patients' survival. An extensive research on a possible mechanism underlying endothelial cell permeability increase is urgently needed.

The decreased permeability is usually found in hypoxicischemic organs [25]. During ischemia, many inflammatory mediators are locally accumulated and capable of disrupting the interendothelial junction assembly, thereby causing endothelial hyperpermeability. Usually, adaptive cellular responses to hypoxia are mediated by HIF-1. Notably, the main burn-induced organ damage is clinically characterized by hypoxemia that activates HIF-1-mediated adaptive cellular responses [26]. Incubating endothelial cells with burn serum, we found an increased HIF-1 $\alpha$ expression that was forcefully proved by decreased FIH-1 expression that negatively controlled cellular level and activity of HIF-1 under hypoxia [16]. Given this, both positive and negative regulators of FIH-1 provide important potential therapeutic targets for drugs that can be used to manipulate HIF-1 expression in burn pathological conditions. 
Due to its ubiquity in mammalian, miRNAs are increasingly explored in various body functions. Importantly, alterations in their levels may compromise cellular function. Accumulating evidence focuses on regulating the role of miRNA on the function of protein expression under cell hypoxic-ischemic conditions [27,28]. Among these, miR-98 was found expressed to the greatest extent during hypoxia in squamous cell carcinoma [14]. Interestingly, we found upregulated miR-98 in rat models of burn and burn serumstimulated rat vascular endothelial cells. We hypothesized the possible involvement of miR-98 in acute post-burn pathophysiologic process. Importantly, we identify the possible target FIH-1 by miR- 98 by result of fluorescent report assay which was further confirmed by protein expression assay showing that silenced miR-98 promoted FIH-1 expression followed with a decreased HIF-1 protein level. These data strongly verify our hypothesis on the possible involvement of miR-98 in acute post-burn pathophysiologic process. In view of the above result, expression change of miR-98 would influence burn-induced vascular hyperpermeability. This was supported by monolayer endothelial cell analysis showing that silenced miR-98 reversed burn serum-induced junction-associated $\mathrm{ZO}-1$ protein as well as hyperpermeability.

\section{Conclusions}

In summary, severe burn injury-induced internal organic hyperpermeability was mediated by upregulated miR- 98 expression that inhibited $\mathrm{FIH}-1$ protein expression to the extent that it activated HIF-1 gene expression, resulting in junction-associated protein deficiency. So, targeting miR-98 that mediate $\mathrm{FIH}-1$ gene expression suppression demonstrates a therapeutic potential to improve vascular barrier function during burn injury.

\section{Abbreviations}

BCA: Bicinchoninic acid; CAD: C-terminal activation domain; DMEM: Dulbecco's Modified Eagle's Medium; EB: Evans blue; FIH-1: Factorinhibiting HIF-1; HIF-1: Hypoxia-inducible factor-1; NIH: National Institutes of Health; PVDF: Polyvinylidene fluoride; RAECs: Rat aortic endothelial cells; SD: Standard deviation; TBSA: Total body surface area; TEER: Transendothelial electric resistance; -1 and ZO-2: Zonula occludens.

\section{Competing interests}

The authors declare that they have no competing interests.

\section{Authors' contributions}

YY and LF carried out the molecular genetic studies, participated in the sequence alignment, and drafted the manuscript. DL carried out the immunoassays. YT participated in the sequence alignment. CW participated in the design of the study and performed the statistical analysis. $\mathrm{DH}$ conceived of the study, participated in its design and coordination, and helped to draft the manuscript. All authors read and approved the final manuscript.

\section{Acknowledgments}

This work was supported by Medical Scientific Research Subject of Anhui's Health Bureau (No.09A067).
Received: 6 January 2015 Accepted: 13 April 2015

Published online: 23 April 2015

\section{References}

1. Huang $\mathrm{Q}$, Zhao $\mathrm{M}$, Zhao K. Alteration of vascular permeability in burn injury. Med Express. 2014;1 (2):62-76.

2. Magnotti LJ, Deitch EA. Burns, bacterial translocation, gut barrier function, and failure. J Burn Care Rehabil. 2005;26(5):383-91.

3. Gosain A, Gamelli RL. Role of the gastrointestinal tract in burn sepsis. J Burn Care Rehabil. 2005;26(1):85-91.

4. Epstein MD, Banducci DR, Manders EK. The role of the gastrointestinal tract in the development of burn sepsis. Plast Reconstr Surg. 1992;90(3):524-31.

5. Turner JR. Molecular basis of epithelial barrier regulation: from basic mechanisms to clinical application. Am J Pathol. 2006;169(6):1901-9. doi:10.2353/ajpath.2006.060681.

6. Steed E, Balda MS, Matter K. Dynamics and functions of tight junctions. Trends Cell Biol. 2010;20(3):142-9. doi:10.1016/.ttcb.2009.12.002.

7. Ogunshola OO, Al-Ahmad A. HIF-1 at the blood-brain barrier: a mediator of permeability? High Alt Med Biol. 2012;13(3):153-61.

8. Liu H, Li M, Wang P, Wang F. Blockade of hypoxia-inducible factor-1alpha by $Y C-1$ attenuates interferon-gamma and tumor necrosis factor-alpha-induced intestinal epithelial barrier dysfunction. Cytokine. 2011;56(3):581-8. doi10.1016/j.cyto.2011.08.023.

9. Kannan KB, Colorado I, Reino D, Palange D, Lu Q, Qin X, et al. Hypoxia-inducible factor plays a gut-injurious role in intestinal ischemia reperfusion injury. Am J Physiol Gastrointest Liver Physiol. 2011;300(5):G853-61. doi10.1152/ajpgi.00459.2010.

10. Hindryckx P, De Vos M, Jacques $P$, Ferdinande $L$, Peeters $H$, Olievier $K$, et al. Hydroxylase inhibition abrogates TNF-alpha-induced intestinal epithelial damage by hypoxia-inducible factor-1-dependent repression of FADD. J Immunol. 2010;185(10):6306-16. doi10.4049/jimmunol.1002541.

11. Keely S, Glover LE, Weissmueller T, MacManus CF, Fillon S, Fennimore B, et al. Hypoxia-inducible factor-dependent regulation of platelet-activating factor receptor as a route for gram-positive bacterial translocation across epithelia. Mol Biol Cell. 2010;21(4):538-46.

12. Zahs A, Bird MD, Ramirez L, Turner JR, Choudhry MA, Kovacs EJ. Inhibition of long myosin light-chain kinase activation alleviates intestinal damage after binge ethanol exposure and burn injury. Am J Physiol Gastrointest Liver Physiol. 2012;303(6):G705-12. doi10.1152/ajpgi.00157.2012.

13. Chen C, Wang P, Su Q, Wang S, Wang F. Myosin light chain kinase mediates intestinal barrier disruption following burn injury. PLoS One. 2012;7(4), e34946. doi10.1371/journal.pone.0034946.

14. Yu D, Marchiando AM, Weber CR, Raleigh DR, Wang Y, Shen L, et al. MLCKdependent exchange and actin binding region-dependent anchoring of ZO-1 regulate tight junction barrier function. Proc Natl Acad Sci U S A. 2010;107(18):8237-41. doi10.1073/pnas.0908869107.

15. Morin-Brureau M, Lebrun A, Rousset MC, Fagni L, Bockaert J, de Bock F, et al. Epileptiform activity induces vascular remodeling and zonula occludens 1 downregulation in organotypic hippocampal cultures: role of VEGF signaling pathways. J Neurosci. 2011;31(29):10677-88. doi10.1523/JNEUROSCI.5692-10.2011.

16. Mahon PC, Hirota K, Semenza GL. FIH-1: a novel protein that interacts with HIF-1alpha and VHL to mediate repression of HIF-1 transcriptional activity. Genes Dev. 2001;15(20):2675-86. doi10.1101/gad.924501.

17. Lando D, Peet DJ, Gorman JJ, Whelan DA, Whitelaw ML, Bruick RK. FIH-1 is an asparaginyl hydroxylase enzyme that regulates the transcriptional activity of hypoxia-inducible factor. Genes Dev. 2002;16(12):1466-71. doi10.1101/gad.991402.

18. Lando D, Peet DJ, Whelan DA, Gorman JJ, Whitelaw ML. Asparagine hydroxylation of the HIF transactivation domain a hypoxic switch. Science. 2002;295(5556):858-61. doi10.1126/science.1068592.

19. Hebert C, Norris K, Scheper MA, Nikitakis N, Sauk JJ. High mobility group A2 is a target for miRNA-98 in head and neck squamous cell carcinoma. Mol Cancer. 2007;6:5. doi10.1186/1476-4598-6-5.

20. Ikezu T, Okamoto T, Yonezawa K, Tompkins RG, Martyn JA. Analysis of thermal injury-induced insulin resistance in rodents. Implication of postreceptor mechanisms J Biol Chem. 1997;272(40):25289-95.

21. Luo HM, Du MH, Lin ZL, Zhang L, Ma L, Wang H, et al. Valproic acid treatment inhibits hypoxia-inducible factor 1alpha accumulation and protects against burn-induced gut barrier dysfunction in a rodent model. PLoS One. 2013;8(10), e77523. doi10.1371/journal.pone.0077523. 
22. Li T, Cai S, Zeng Z, Zhang J, Gao Y, Wang X, et al. Protective effect of polydatin against burn-induced lung injury in rats. Respir Care. 2014;59(9):1412-21. doi10.4187/respcare.02831.

23. Jeschke MG, Chinkes DL, Finnerty CC, Kulp G, Suman OE, Norbury WB, et al. Pathophysiologic response to severe burn injury. Ann Surg. 2008;248(3):387-401. doi10.1097/SLA.0b013e3181856241.

24. Shen Q, Wu MH, Yuan SY. Endothelial contractile cytoskeleton and microvascular permeability. Cell Health Cytoskeleton. 2009;2009(1):43-50.

25. Xiao R, Huang YS, Lei ZY. [Influence of myocardial inhibition on injury to liver, kidney and intestine at early stage in rat with severe scald]. Zhonghua Shao Shang Za Zhi. 2009;25(3):176-9.

26. Semenza GL. Hypoxia-inducible factors in physiology and medicine. Cell. 2012;148(3):399-408. doi10.1016/j.cell.2012.01.021.

27. Peng Z, Li J, Li Y, Yang X, Feng S, Han S, et al. Downregulation of miR-181b in mouse brain following ischemic stroke induces neuroprotection against ischemic injury through targeting heat shock protein A5 and ubiquitin carboxyl-terminal hydrolase isozyme L1. J Neurosci Res. 2013;91(10):1349-62.

28. He B, Xiao J, Ren AJ, Zhang YF, Zhang H, Chen M, et al. Role of miR-1 and miR-133a in myocardial ischemic postconditioning. J Biomed Sci. 2011;18:22. doi10.1186/1423-0127-18-22.

\section{Submit your next manuscript to BioMed Central and take full advantage of:}

- Convenient online submission

- Thorough peer review

- No space constraints or color figure charges

- Immediate publication on acceptance

- Inclusion in PubMed, CAS, Scopus and Google Scholar

- Research which is freely available for redistribution 